\title{
Experiência religiosa e Psicologia: contribuições da fenomenologia segundo Ales Bello
}

\author{
Psychology and religious experience: contributions \\ of phenomenology according to Ales Bello
}

\section{Marcio Luiz Fernandes*}

\section{Resumo}

A abordagem de Ales Bello constitui uma referência importante para a compreensão dos processos e relações estabelecidas entre a fenomenologia e a psicologia, sobretudo no que se refere às pesquisas qualitativas realizadas no Brasil. A comunidade humana e intelectual, criada em torno da escola romana de fenomenologia sob a inspiração dos seus trabalhos, coloca em prática um procedimento metodológico em círculos concêntricos, cujo objetivo é realizar um processo contínuo de aprofundamento das questões em torno da subjetividade e do sentido do sagrado. Do ponto de vista da história da psicologia,

* MLF: Doutor em Psicologia, e-mail: marciovisconde@yahoo.com.br 
é necessário lembrar que a própria fenomenologia nasceu a partir da solicitação e das ambições da nascente ciência, a fim de oferecer à pesquisa psicológica as necessárias indicações para as perguntas a respeito do significado da vida psíquica e dos atos psíquicos. Neste particular, a contribuição de Ales Bello foi significativa, porque no âmbito da psicologia acadêmica brasileira ela indicou que o retorno às fontes da pesquisa fenomenológica permitiria não somente compreender o que representava esta nova escola filosófica, mas revelou a estreita relação de Husserl e seus discípulos na elaboração das bases teóricas para a psicologia.

Palavras-chave: Fenomenologia e psicologia. Ales Bello. Experiência religiosa.

\section{Abstract}

Ales Bello's approach is an important reference to the understanding of the processes and relations between phenomenology and psychology, especially regarding the qualitative research conducted in Brazil. The human and intellectual community, built around the Roman phenomenological school under the inspiration of her work, puts into action a methodological procedure in concentric circles, whose aim is to implement a continuous process of deepening into questions about the subjectivity and the sense of the sacred, of things of the world and about humanity. From the point of view of the history of psychology, it is necessary to remember that the very phenomenology was born from the requests and ambitions of a nascent science in order to offer to the psychological research sufficient parameters to questions about the meaning of psychic life and psychic acts. Regarding to that, the contribution of Ales Bello was significant because, within the Brazilian academic psychology, she indicated that the return to the sources in the phenomenological research would not only allow the understanding of what represented that new philosophical school, but it would also bring into light the close relationship between Husserl and his disciples during the elaboration of a theoretical basis for psychology.

Keywords: Phenomenology and Psychology. Ales Bello. Religious experience. 


\section{Introdução}

O objetivo deste artigo será o de apresentar as ideias de uma filósofa de origem romana, diretora do Centro Italiano de pesquisas fenomenológicas e professora emérita de história da filosofia Contemporânea da Universidade Lateranense, que devotou sua existência à pesquisa fenomenológica. Ora, para descobrir o significado e a pertinência dos estudos da fenomenologia de Husserl e Edith Stein e a respectiva fundamentação antropológica oferecida à psicologia, à teologia e às ciências humanas em geral, por parte de Angela Ales Bello seguiremos as trilhas de seus escritos. No entanto, antes de adentrarmos na descrição de sua posição filosófica, será necessário perceber como ela mesma apresenta a origem e o significado daquele início de colaboração, a qual favorecerá fecundas e originais sínteses por parte de pesquisadores e estudantes brasileiros no âmbito da psicologia, da filosofia e da teologia:

Quando a profa. Dra. Jacinta Turolo Garcia me convidou para participar de uma série de atividades acadêmicas na Universidade do Sagrado Coração da qual ela era então a reitora, cheguei ao Brasil em 11 de setembro de 2001 (justamente naquele dia!) e encontrei um ambiente extremamente acolhedor, desejoso de estabelecer intercâmbios culturais com a Europa e particularmente com a Itália. Um ambiente caracterizado pela humildade que deriva da sabedoria. E tal sabedoria se mostrava também no evento que me conduzira até ali: tratava-se de um congresso sobre a pesquisa qualitativa em psicologia, algo absolutamente desconhecido na Itália. Logo compreendi que o projeto era importante e inovador frente ao que prevalecia na Europa em termos de psicologia (ALES BELLO, 2013a, p. 9).

No prefácio ao livro sobre o Brasil, escrito pelo intelectual suíço, jornalista e dramaturgo Stefan Zweig (1881-1942), emergem os traços significativos da postura humana e intelectual da filósofa quando, evocando as recordações de sua primeira visita ao Brasil, afirma que a possibilidade para eliminar os preconceitos acontece de forma simples, ou seja, é necessário tempo e conhecimento direto: 
Foram necessários onze anos de frequentação, com contatos humanos e intelectuais precisos, como aqueles que podem fornecer o ensino nas universidades brasileiras, para poder afirmar que eu compreendi alguma coisa deste. [...] Parece que o harmonizar seja um traço distintivo do povo brasileiro, que tende mais a sublinhar as semelhanças que as distinções; é um povo que se mescla (ALES BELLO, 2013b, p. 7).

De fato, o Brasil será para ela o "lugar mágico onde se realizava o sonho de Husserl e de Stein de fornecer às ciências humanas uma base filosófica, fenomenológica" (ALES BELLO, 2013b, p. 11) e com o qual a pesquisadora italiana estabelecerá profícuos laços de amizade intelectual para a difusão do pensamento fenomenológico. Verducci (2011) recorda-nos que, a especificidade da obra filosófica da autora em questão está na forma de abordar os autores da história da filosofia a partir da valorização - como se nota nos relatos acima - do tema da subjetividade, da empatia, do sagrado e na capacidade de traduzir e nos fazer viver a herança fenomenológica na pós-modernidade. Os temas abordados na sequência elucidam, na sua brevidade, uma série de questões de grande relevância teórica e, além disso, sinalizam para o significado de como o conhecimento pode acontecer no exercício concreto de uma amizade.

\section{Fenomenologia e psicologia}

As relações entre a fenomenologia e a psicologia, sobretudo no que se refere às pesquisas qualitativas realizadas no Brasil, como já foi assinalado acima, foram objeto da atenção da filósofa em suas visitas acadêmicas ao país (MAHFOUD; MASSIMI, 2013). Os estudos principais podem ser examinados em livros e em artigos escritos para numerosas revistas. Os cursos ministrados no Brasil, principalmente nos departamentos de psicologia da USP de Ribeirão Preto e na Universidade Federal de Minas Gerais, documentam como no campo da fenomenologia se pode realizar a interconexão das áreas da filosofia, psicologia e religião. No livro Fenomenologia e Ciências humanas: psicologia, história e religião (ALES BELLO, 2004) temos o registro daquilo que os estudiosos chamam de uma fenomenologia voltada para o concreto, isto é, realista. Já em Pessoa e comunidade (ALES BELLO, 2015a), 
também fruto das transcrições das aulas ministradas sobre Edith Stein com a análise detalhada a respeito do livro Psicologia e Ciências do Espírito de Stein - propõe-se a explicação dos conceitos fundamentais da fenomenologia e a base antropológica de compreensão dos dinamismos humanos e, assim, discutem-se as vivências da esfera psíquica e aquelas da esfera da consciência, a pessoa e sua relação com a comunidade e as implicações de sua ação na história do ponto de vista da sociedade. Outrossim, estas lições foram fundamentais para superar preconceitos presentes no contexto universitário brasileiro com relação à difusão de ideias de que a fenomenologia não estava atenta aos processos históricos e que falar de essência como estrutura fundamental do fenômeno era um tema superado (MAHFOUD, 2015, p. 16).

No Brasil, diferentemente do que acontece na Europa, está se realizando o projeto original dos fenomenólogos, cuja preocupação era oferecer uma descrição filosófica do ser humano que pudesse servir de base para justificar a sua complexa estrutura (ALES BELLO, 2013a). Sendo assim, a fundamentação antropológica que a psicologia encontra na fenomenologia clássica, leva em conta o exame do ser humano na variedade das características presentes em sua estrutura. Na análise proposta por Husserl, a atenção volta-se para a consciência como lugar do fluir das experiências vividas, captadas intuitivamente e que permitem ao sujeito constituir um mundo a partir delas. Sob este aspecto, as experiências vividas ajudam não só ao conhecimento do mundo externo, mas é útil para descortinar as dimensões humanas ali presentes, tal como exemplifica a própria filósofa:

A percepção, que nós seres humanos vivemos, coloca-se em ação por meio das sensações e estas nos conduzem descoberta da corporeidade. Já o desejar, o ser atraído ou a vivência dos impulsos instintivos nos remetem àquele território que se pode definir como psique. Enquanto que os atos de avaliação, de reflexão e de decisão são relativos à dimensão espiritual, cujo termo espiritual indica aquilo que é especificamente humano e que o distingue do mundo animal (ALES BELLO, 2014b, p. 19).

Ora, a entrada em cena deste tipo de análise do ser humano altera profundamente a perspectiva. A reflexão sobre a estrutura tripartida em corpo, psique e espírito foi objeto de atenção de todos os filósofos na tradição, 
contudo, a novidade da fenomenologia foi mostrar como se pode justificar esta estrutura a partir da análise das vivências. Neste particular, a filósofa indicou que o retorno às fontes da pesquisa fenomenológica permitiria não somente compreender o que representava esta nova escola filosófica, mas revelou a estreita relação de Husserl e seus discípulos na elaboração das bases teóricas para a psicologia. A descrição proposta por Husserl caracteriza-se por três momentos fundamentais: é um procedimento, em primeiro lugar, de caráter reflexivo no qual emerge a intuição que, em seguida, visa compreender o significado das coisas e, por fim, reconstruir a experiência e não interpretá-la. Então, manifesta-se neste horizonte a dupla direção desta descrição: de um lado as investigações das vivências dos sujeitos, a questão da interioridade e, por outro, a análise das concepções de mundo, partindo das dimensões intersubjetivas (ALES BELLO, 1998, p. 36). E assim, vemos que a relação entre a psicologia e a fenomenologia não está restrita apenas ao reconhecimento da esfera da subjetividade e do fluir das vivências do ser humano, antes, tal relação representa a descoberta da extraordinária correspondência entre o território da dimensão psíquica do ser humano e o universo da consciência transcendental elaborado por Husserl, com suas preocupações com o mundo da vida como mundo das culturas (ALES BELLO, 2016a, p. 28-34).

Neste sentido, a contribuição da fenomenóloga italiana aos estudiosos da psicologia refere-se, em primeiro lugar, à minuciosa descrição sobre a forma de proceder do método husserliano, a fim de captar as coisas mesmas e, em segundo lugar, à explicitação por meio do conceito de vivência dos atos característicos da interioridade humana que permitem um conhecimento qualitativo a respeito dos estados psíquicos. É verdade que, em termos gerais, é notável a competência acadêmica \intelectual e o rigor filosófico derivado de suas reflexões, mas será necessário reconhecer, como o diz Mahfoud (2015, p. 12), "não apenas seus textos, mas que a sua presença mesma tem sido provocadora, gerando cuidado com a própria experiência e com o próprio trabalho por parte de muitos". Aliás, a este respeito os autores Ghigi (2003); Verducci (2011); Massimi e Mahfoud (2011); Alfieri (2014); Shahid e Cortellesi (2015); Garcia Turolo e Goto Akira (2016) e Cortellesi (2016) convergem em afirmar não só o valor das suas obras filosóficas, mas 
a capacidade de trabalhar no espírito da escola fenomenológica e indicar o estilo e o método para uma análise em profundidade sobre o ser humano.

A trajetória de formação e difusão de tal escola de pensamento no âmbito da psicologia brasileira foi responsabilidade de Miguel Mahfoud e Marina Massimi (ALES BELLO, 2013a, p. 13) com o intuito de fazer notar aos estudantes, psicólogos e pesquisadores que a fenomenologia propõe uma antropologia filosófica e conceitos operativos que permitem a compreensão unitária do ser humano. Do ponto de vista da história da psicologia, é necessário lembrar que a própria fenomenologia nasceu a partir da solicitação e das ambições da nascente ciência, a fim de oferecer à pesquisa psicológica as necessárias indicações para as perguntas sobre o significado da vida psíquica e dos atos psíquicos. Desse modo, é preciso destacar que autores como Edmund Husserl, Edith Stein, Conrad Martius, Max Scheler, Alexander Pfander, Maurice Merleau-Ponty, Karl Jaspers, Gabriel Marcel, Ludwig Binswanger e outros, estavam preocupados em oferecer uma proposta epistemológica - explícita ou implícita - à psicologia que fosse adequada ao estudo das vivências do ser humano (ALES BELLO; DE LUCA, 2005).

Mahfoud e Massimi (2011; 2015) enfatizam, por outro lado, que para descobrir o valor da edição e difusão dos textos da filósofa italiana em português será preciso um recuo na história. A psicologia brasileira, nos últimos cinquenta anos do século XX, recebeu as influências da psicologia funcionalista americana da análise experimental do comportamento e da forte recepção da psicanálise, fazendo com que outras referências filosóficas penetrassem em medida muito menor nos estudos psicológicos. Assim, é neste contexto que se deve ler a inserção e a difusão da peculiar proposta husserliana e steiniana no mundo da psicologia acadêmica brasileira por parte de Ales Bello.

Vê-se por aí, mesmo que de modo sutil, que a fenomenologia clássica e a psicologia, enquanto campos de conhecimento, são relacionáveis e a primeira tem uma função de oferecer a fundamentação para a segunda e sem apropriação desta perspectiva "corre-se o risco de não reconhecer novas formas de idealismo propostas atualmente mantendo-nos atados à abstração, sem responder às provocações que nosso momento histórico-cultural nos faz" (MAHFOUD, 2015, p. 14). 


\section{Culturas e religiões}

Outro núcleo fundamental de discussão é relativo ao tema da pluralidade das culturas e das religiões. A pergunta de fundo é como seria possível justificar que o ser humano conserve uma unidade fundamental apesar das diferentes visões de mundo que caracterizam cada grupo étnico, religioso e cultural. A abordagem fenomenológica apresenta-se como um instrumento interessado em evidenciar o mundo-da-vida, isto é, o conjunto das vivências compartilhadas pelo ser humano com o seu grupo de pertença. De fato, "a eficácia da fenomenologia, justamente por ser uma postura anti-especulativa, não pode ser testada a não ser na pesquisa de campo e na análise dos fenômenos que despertam a atenção" (ALES BELLO, 1998, p. 13). É necessário um trabalho como o do arqueólogo que realiza uma operação de escavo. A rigor, a posição de Husserl, no caso específico, exige a postura da epoché, este abster-se de julgar que leva a apreender o sentido contido naquilo que nos aparece. A epoché, para Ales Bello, tem o sentido de uma profunda disponibilidade para mudar de posição. Para Husserl, é necessário que o psicólogo realize esta operação porque é a porta de entrada que torna possível considerar o mundo na sua validade para todos os sujeitos e perceber "a recíproca implicação dos fluxos de vida de cada um dos sujeitos". A arqueologia fenomenológica, portanto, quer colocar em evidência uma estrutura comum no interior do fenômeno religioso que possibilite posteriormente trabalhar as questões da inter-religiosidade e da inter culturalidade. Neste sentido, a filósofa afirma que a arqueologia fenomenológica é o instrumento mais idôneo para poder realizar uma investigação profunda das culturas e das religiões porque:

Permite estabelecer a função própria da religião e não reduzi-la a outras dimensões, a psicológica ou a sacral, e também não eliminá-la em favor do âmbito puramente intelectual. $\mathrm{O}$ terreno fenomenológico por ele oferecido permite, portanto, afrontar a questão da pluralidade das religiões, ligando-a à pluralidade das culturas, mas estabelecendo uma hierarquia, porque cultura e religião não estão lado a lado, são subordinadas, no sentido de que a religião, oferecendo a visão do mundo mais ampla e totalizante, está na base das perspectivas culturais. Isso é válido também no caso das culturas laicizadas, 
porque também o afastamento da dimensão religiosa é uma escolha que tem como referência esta mesma dimensão que rejeita: quem se declara laicista o faz referindo-se à possibilidade não aceita de ser religioso (ALES BELLO, 2016a, p. 157).

Este tipo de arqueologia fenomenológica faz o estudioso prestar atenção aos processos humanos na sua unidade. A proposta feita por Ales Bello "revela que os dados sensíveis são materiais para as formações intencionais e isto permite uma aproximação a processos culturais ligados à esfera da materialidade (hilética), processos muito relevantes e difusos na realidade do Brasil" (MAHFOUD; MASSIMI, 2011, p. 809).

A filósofa afirma a tese de que a religião tem sempre uma função de justificação profunda da cultura e de que todos os fenômenos culturais têm uma raiz religiosa. Recentemente, retomou o tema interrogando-se sobre o sentido do sagrado (ALES BELLO, 2014b), por meio de uma análise sobre as características do comportamento religioso e dos processos que vão desde o sacro arcaico ao sacro complexo, chegando à conclusão de que o tema antropológico é o pressuposto necessário para compreender o fenômeno religioso, seja a partir dos comportamentos de aceitação e reconhecimento de uma Potência quanto da sua rejeição e dos respectivos processos de dessacralização.

Desse modo, seguindo o método da Escola fenomenológica, ela propõe o aprofundamento da análise do fenômeno religioso realizado por Gerardus van der Leeuw junto com as contribuições de Husserl. Com as indicações destes dois autores é possível avançar nas pesquisas sobre o significado da experiência religiosa quod nos e, desse modo, descobrir por meio do momento hilético e noético como tal experiência se apresenta em si. Os exemplos de escavo fenomenológico a partir das diversas culturas como a hinduísta, a budista, a africana e a comparação com a cultura ocidental de vertente cristã, no seu crescente processo de dessacralização e da retomada do ateísmo, ilustram o significado da pesquisa da filósofa (ALES BELLO, 1998; 2009a; 2014b).

A análise do fenômeno religioso, porém, tem uma peculiaridade: deverá articular o objeto da experiência religiosa com as questões referentes às relações entre o feminino e o masculino; o pensar e o crer; a teologia e a filosofia, a revelação e a mística (ALES BELLO, 1998). A leitura e atualização 
da contribuição da escola fenomenológica alemã realizada deste modo permitem-nos pensar as questões de uma filosofia da mística, bem como das relações entre a fenomenologia e a teologia. A experiência religiosa é uma experiência de si e da existência de algo superior a si. Aqui, a noção de experiência enquanto compreensão do sentido é fundamental, pois trazemos dentro a marca do ilimitado e do ponto de vista fenomenológico. Pode-se analisar esta corrente de consciência de tipo religioso por meio de um processo racional, indagando as razões das vivências: "O ser humano pode refletir e, portanto, racionalizar; trata-se da via subjetiva que se encontra em Santo Agostinho, Santo Anselmo, Descartes e também em Husserl" (ALES BELLO, 2006, p. 101).

A interioridade passa a ser o centro unificante e a caixa de ressonância das experiências silenciadas e fragmentadas. A imanência vem reconhecida como um dos lugares da manifestação da divindade "enquanto não se trata de uma projeção por parte do sujeito humano, mas de uma extraordinária invasão do seu território pessoal por parte da potência que o supera" (ALES BELLO, 2003, p. 11-25). Nesta perspectiva, o exame da experiência religiosa e, em particular, da mística exige uma reflexão de tipo fenomenológica como proposta por Ales Bello. A tese demonstrada em seus escritos é justamente que, tanto a teologia negativa quanto a mística podem ser compreendidas sobre a base de uma investigação na qual se leve em consideração a relação entre a noética e hilética. Lendo, por exemplo, as poesias de Al-Hallag, místico sufi do III século a respeito dos êxtases divinos, pode-se notar semelhanças com as descrições dos Santos carmelitanos. Nestes textos, místicos emergem descrições de uma presença sensível que envolve a pessoa na sua totalidade, com forte acento sobre a esfera da sensibilidade humana. A autora sublinha que estes textos são reveladores de um extraordinário caminho interior. Provavelmente Edith Stein diria que são iluminações que dispõe o ser humano a abrir-se à graça santificante para poder, depois, chegar à união com Deus. É interessante notar ainda que, os textos dos místicos das diferentes tradições religiosas - a partir da vivência por eles narrada — assinalam uma grande abertura ao diálogo inter-religioso. E não apenas com as tradições religiosas monoteísticas, mas também com as religiões e crenças culturalmente distantes. $\mathrm{O}$ que significa que existe um terreno comum, um lugar profundo interior, um elemento identitário presente em todos os seres 
humanos. E ali existe Deus, ali Ele se manifesta. No entanto, para a filósofa, o importante é mostrar, por meio da análise fenomenológica, a dignidade cognitiva da "revelação mística que, utilizando também - mas não somente - as potencialidades essenciais do ser humano, é capaz de fazer emergir a Presença, profunda e inexaurível, que vive em cada um de nós" (ALES BELLO, 2009b, p. 47).

É necessário hoje - na situação cultural contemporânea - no qual se nota o difuso interesse pela questão da religião, colocar-se de novo a questão: o que é a experiência religiosa, trata-se de uma ilusão coletiva? Ales Bello procura responder a questão partindo de uma perspectiva invertida, ou seja, apresenta uma reflexão sobre o fenômeno da negação, do ateísmo e discute principalmente as argumentações do filósofo Feuerbach, porque elas são continuamente utilizadas para justificar a negação da existência de Deus e para destacar o caráter ilusório da abertura religiosa. E hoje ouve-se comumente falar da religião como se fosse uma projeção de alguma coisa, fruto da fantasia, não possuidora de alguma validade e, consequentemente, se deseja a libertação desse comportamento de submissão àquilo que não tem alguma consistência. Ele, portanto, interpreta a experiência religiosa como fruto da alienação e da projeção daquilo que se deseja ser mas não se é. A questão é que Feuerbach examina apenas a vivência psíquica do ser humano: coloca o sucesso do Cristianismo a partir do desejo do ser humano de superar seus limites, de ser amado. Já Ales Bello, na perspectiva fenomenológica, faz a distinção entre a esfera psicológica e aquela das vivências, propondo a reflexão sobre o limite e precariedade do ser humano:

A resposta ao ateísmo ocorre, em primeiro lugar, na vertente subjetiva e, uma vez liberado o caminho da ilusão do fenômeno religioso e após captar a sua irredutibilidade a outro objeto, podemos observar que o próprio ateísmo busca uma resposta global, absoluta e, mesmo fechando os olhos a respeito do poder, transferindo-o para um nível humano, deve admitir que o ser humano volta a se apresentar sempre com a sua insuficiência. Pode até fingir que se contenta com ela, mas desse modo trona a própria insuficiência um absoluto, sem ser capaz de responder às perguntas: por que procurar aquilo que satisfaz plenamente?; de onde tira o ser humano a ideia de poder ser perfeito e poderoso e a consciência de não poder sê-lo?; de onde vem a consciência? (ALES BELLO, 1998, p. 167). 
Pode-se observar, portanto, que o desejo nasce de uma falta na comparação com uma plenitude e, o limite, nasce da consciência do ilimitado. E se nós somos seres finitos, como podemos pensar o infinito? A resposta válida segue a linha da prova ontológica de Santo Anselmo, segundo a qual nós já conhecemos, mesmo de modo imperfeito, alguma coisa que nos supera e que se configura como algo Potente e Absoluto. Tal conhecimento não pode provir de nós que somos limitados, mas nos é dada pelo próprio Ilimitado, trata-se aqui de uma argumentação racional que atravessou a história da filosofia desde Platão até Agostinho, de Anselmo até Descartes, até Husserl e Edith Stein. Pode-se dizer, então, que a "experiência religiosa consiste no movimento que inicia pelas marcas deixadas por Deus na parte mais profunda do núcleo [...] e que passa através do impulso de confiança próprio da psique, a qual segue a adesão da afetividade, do sentimento e do intelecto" (ALES BELLO, 2009b, p. 37).

\section{Psicologia da religião e psicopatologia fenomenológica}

A discussão sobre os temas relativos à psicologia da religião e a psicopatologia fenomenológica constitui o centro do livro intitulado O sentido do humano: entre fenomenologia, psicologia e psicopatologia (ALES BELLO, 2016b) e dedicado pela autora aos amigos brasileiros psicólogos e psicoterapeutas. Nesta obra, o sentido da experiência religiosa para o ser humano é investigado tanto do ponto de vista psicológico quanto filosófico-fenomenológico e, em particular, a partir do tema da psicopatologia das religiões.

Para Ales Bello, a psicologia da religião é uma das disciplinas por meio das quais se confirma o quanto a religiosidade constitui um centro de orientação para o ser humano. Como a história desta disciplina é muito breve, ela opta por apresentar os traços essenciais que a caracterizam por meio de algumas figuras representativas. Como é o caso de Gordon W. Allport (18971967) nos Estados Unidos e o de Antoine Vergote (1921-2013) no âmbito europeu ilustrando como ambos tiveram preocupações com relação ao estatuto epistemológico do referido território de pesquisa e eram conscientes da extrema complexidade do fenômeno religioso. $\mathrm{Na}$ linha de Allport, por 
exemplo, pode-se dizer que a religião oferece uma visão que dá unidade à vida e, de fato, segundo ele a psicologia "não pode impedir a compreensão das capacidades religiosas do homem, se quer ser, no pleno sentido da palavra, um logos da psique humana" (ALLPORT, 1968, p. 137). Em Vergote, por outro lado, é interessante notar a ênfase no aspecto da religião como algo observável, por meio das vivências dos sujeitos, e caracterizado pelos nexos de influência recíproca entre os elementos psíquicos e os símbolos da religião que devem ser considerados em qualquer interpretação. Para Ales Bello a contribuição deste autor encontra-se no fato dele não sustentar que a religião se identifique com um comportamento puramente psíquico, mas descobrir que o encontro do ser humano com a potência religiosa produz seus efeitos, a tal ponto, de os símbolos imprimirem o seu próprio selo no psiquismo. Desse modo, a religião não é uma criação psíquica, mas um dado presente no ambiente que exige do indivíduo "uma tomada de posição frente a tais símbolos, podendo acolhê-los, valorizá-los e vivificá-los, ou também, rejeitá-los; mas tanto a fé quanto o comportamento de rejeição tornam-se objetos de estudo da psicologia da religião" (ALES BELLO, 2016b, p. 107).

Nos estudos de Allport, de Vergote, de Aletti e de Fizzotti se podem constatar, conforme anota Ales Bello (2016b, p. 109), algumas afinidades com o modo de entender a análise da psique e da experiência religiosa proposta pela escola fenomenológica. Estes estudiosos compreendem o comportamento religioso na sua dinamicidade e a partir de um processo que abarca a totalidade da existência do sujeito e o envolve desde a esfera racional àquela dos afetos, valores e sentimentos. No entanto, a ligação mais direta com a análise filosófico-fenomenológica provém dos estudiosos que se dedicaram a observar a dinâmica dos distúrbios psíquicos. É o caso, por exemplo, de Bruno Callieri que dedicou-se a investigar as experiências de percepção do fim do mundo "cujo aspecto catastrófico é acompanhado da presença de vivências religiosas que permitem a quem as experimenta de aproximar-se de cenários diversos com relação ao mundo da vida no qual estamos imersos" (ALES BELLO, 2016b, p. 110). 


\section{Edith Stein e a psicologia}

Ales Bello soube desenvolver ao longo dos anos um interessante processo de aprofundamento da proposta teórica de Stein, nas direções mais complexas possíveis, com a atualização deste pensamento nos mais variados contextos. Em primeiro lugar, em termos históricos, realizou a descrição do itinerário de pesquisa de Edith Stein mostrando que o grupo de estudiosos da fenomenologia revelava, ao contrário de outros grupos filosóficos, grande abertura com relação às questões religiosas e promoveu a inserção da reflexão das mulheres no campo cultural (ALES BELLO; ALFIERI; SHAHID; 2011). No prefácio ao livro Edith Stein: a paixão pela verdade a autora apresenta os critérios com os quais realizou sua especulação e, observa que a separação entre a atividade intelectual e a experiência existencial-espiritual do sujeito gera o frio intelectualismo que eticamente não condiz com a tarefa social do intelectual:

Cada vez que me preparo para escrever sobre Edith Stein, sinto-me em conflito entre duas exigências: a de divulgar seu pensamento e a de evitar fazê-lo para não violar o "segredo" de sua alma. De fato, ao narrar esta personagem, não é possível separar a contribuição intelectual da vivência existencial e espiritual que a acompanha. Tal separação, na realidade, não seria lícita para nenhum pensador, mas ao traçar as linhas da história da filosofia, tornou-se hábito realizar esta operação pela tendência a nuclear os resultados da especulação e com eles constituir uma trama conceitual que muitas vezes é alheia à pessoa que a produziu (ALES BELLO, 2014a, p. 17).

Em segundo lugar, na perspectiva da antropologia filosófica, foi ela quem nos indicou por meio de comentários a cada obra de Edith Stein particularmente nos prefácios à edição italiana — os núcleos problemáticos e as categorias fundamentais para a leitura dos textos fenomenológicos. Tais orientações de leitura apresentam um mapa amplo dos temas, figuras e problemas da abordagem fenomenológica. Particularmente significativas são o conjunto de argumentos nas quais aparece a relação entre a fenomenologia de Husserl e a pesquisa fenomenológica de Stein (ALES BELLO; ALFIERI, 2015). A comunidade de pensadores que se dedicam a colocar em evidência a ligação entre os dois estão, por sua vez, vinculados a duas instituições 
significativas: de um lado o Centro italiano de Pesquisas Fenomenológicas, afiliado ao The World Phenomenology Institute (USA) e, por outra parte, a recente fundação da Área Internacional de Pesquisa sobre Edith Stein na filosofia contemporânea que tem sua sede na Pontifícia Universidade Lateranense. A tese defendida - que caracteriza também a orientação comum do grupo de pesquisa - versa sobre a necessidade de um conhecimento aprofundado de Husserl para poder entender, de modo válido, aquilo que Edith Stein expôs nas suas primeiras obras e naquelas sucessivas ao encontro com a filosofia cristã:

É necessário, de fato, observar que também para a compreensão de cada um dos que foram formados na escola de Husserl, mesmo aqueles que se distanciaram, é necessário um conhecimento aprofundado do método de Husserl e dos resultados de sua pesquisa. [...] não é possível conhecer o pensamento de Edith Stein sem referir-se a Husserl (ALES BELLO, 2015b, p. 9).

Na Itália realizou-se uma obra de promoção do pensamento de Edith Stein que se tornou modelo para as nações de diversos continentes. A bibliografia internacional sobre os estudos de Stein, compilada por Alfieri (2012), permite constatar que os estudiosos italianos foram os primeiros a oferecer uma reconstrução da fenomenologia de Stein no confronto com Husserl e o conjunto dos colegas da escola fenomenológica. Além disso, a competência e familiaridade com o pensamento antigo e medieval levou-os a estudar as relações de Stein com os máximos expoentes do pensamento como Agostinho, Tomás, Anselmo e Duns Scoto. No entanto, estas estreitas e complexas relações de confronto com o pensamento husserliano permanecem ainda inexploradas em outros continentes (ALES BELLO, 2014c, p. 164-165).

Nesta direção, outro elemento fundamental posto em evidência nestas pesquisas foi uma interpretação do pensamento de Stein a partir da categoria de harmonia. No livro Edith Stein o dell 'armonia parte-se da tese de que a palavra harmonia representa uma ótima chave de leitura para compreender o sentido profundo da própria pesquisa de Stein. A sua capacidade de perceber a unidade na diferença e estabelecer harmonia entre os pólos opostos como fé-razão; hebraísmo-cristianismo; corpo-alma; indivíduo-comunidade; masculino-feminino passa a ser um critério útil para "compreender em termos culturais a fragmentação do saber que caracteriza diversos setores 
de nossa cultura ocidental" (ALES BELLO, 2009b, p. 240). Ressalta-se que a postura de Stein é nova dentro da história da filosofia porque o resultado que extrai de suas análises nasce a partir de uma radical disponibilidade em ver e escutar, "através da qual é possível captar aquilo que se apresenta essencialmente [...] e permite uma série de investigações que não pressupõem nenhum sistema" (ALES BELLO, 2000, p. 266).

A filósofa destaca a capacidade de Stein de colocar em evidência aquilo que se manifesta de modo positivo na experiência e a busca realizada em suas primeiras obras, na investigação sobre o ser humano, pelo equilíbrio entre a realidade psíquica do indivíduo e a força representada pelo sentir comunitário. A harmonia como descoberta da unidade revela a grande sensibilidade da pensadora alemã em acolher todas as fontes do saber e chegar a um conhecimento solidamente embasado no plano teórico (ALES BELLO, 2000; 2009b; 2014a). No caso da análise da experiência religiosa - lugar central na pesquisa de Edith Stein — trata-se de um procedimento que leva em consideração dois passos fundamentais do método: o primeiro relativo a uma atitude descritiva a respeito das vivências subjetivas e intersubjetivas; já o segundo passo é a disponibilidade para analisar conteúdos e vivências culturais diferentes que exigem a superação dos preconceitos já estabelecidos. A reflexão sobre a experiência religiosa na vertente fenomenológica tem como pressuposto uma análise das vivências no nível antropológico, em comparação com as manifestações religiosas historicamente identificadas e consiste na busca pelos elementos característicos - essenciais - que expressam o desejo do ser humano de encontrar o sentido, a potência, o mistério.

\section{Considerações finais}

Por meio de um rigoroso diálogo com todos os autores da Escola Fenomenológica, com os antropólogos culturais, com os historiadores da religião, psiquiatras e psicólogos da religião - particularmente Allport, Vergote, Aletti e Fizotti - Ales Bello oferece às ciências humanas uma perspectiva analítica e teórica para as investigações do campo religioso. As marcas da sua pesquisa são expressas pela harmonia entre o espírito crítico e o posicionamento construtivo na proposição do conhecimento. Além 
disso, é um trabalho caracterizado por uma exigência de reconhecimento de que na base da cultura humanista e científica se encontra a centralidade do ser humano. Por esta razão, ela faz a escolha por uma perspectiva teórica não redutiva como é aquela proposta pela descrição de Husserl, Stein e seus discípulos por entender que nesta abordagem é possível tornar mais clara a complexidade e estratificação do ser humano no vasto universo de suas manifestações.

Segundo observa Barreira (2013) o trabalho da filósofa italiana tem transformado as análises de cunho antropológico por nos fazer perceber a necessidade de valorizar, de modo equilibrado, as dimensões noéticas e hiléticas. Em pesquisas sobre a cultura brasileira e latino-americana onde a dimensão sensorial, dos impulsos, da intencionalidade e da corporeidade são tão valorizados, o realce dado a este momento hilético pré-categorial junto com o exercício intelectual e analítico podem oferecer melhores resultados em termos de aprendizado sobre como colher as vivências.

Por fim, outra característica fundamental é que se trata de uma pesquisa fenomenológica em círculos concêntricos, onde cada tese ou tema representa um território novo que deve ser examinado voltando às fontes do próprio método seguindo as etapas de análise indicadas por Husserl. As recentes publicações de Ales Bello (2013c; 2014b; 2016a; 2016b) explorando o problema do sentido e do modo como conhecemos e organizamos o conjunto de coisas de nossa vida cotidiana constitui um exemplo de uma investigação em círculos concêntricos, que inicia "de nós mesmos para compreender, em primeiro lugar, como somos feitos, depois, como é feita a natureza e, por fim, o que é o sagrado para nós" (ALES BELLO, 2016a, p. 6).

\section{Referências}

ALES BELLO, A. Cultura e religiões: uma leitura fenomenológica. Trad. AntonioAngonese. Bauru-SP: EDUSC, 1998.

ALES BELLO, A. A fenomenologia do ser humano. Trad. Antonio Angonese. Bauru-SP: EDUSC, 2000. 
ALES BELLO, A. Fenomenologia e Ciências Humanas. Trad. Miguel Mahfoud e Jacinta Turolo Garcia. Bauru: EDUSC, 2004.

ALES BELLO, A; DE LUCA, A. Le fonti fenomenologiche della psicologia. Pisa: Edizioni ETS, 2005.

ALES BELLO, A. Introdução à Fenomenologia. Trad. Miguel Mahfoud e Marina Massimi. Bauru-SP: EDUSC, 2006.

ALES BELLO, A. Il sacrifício del sacro alladesacralizzazione. Memorandum, Belo Horizonte, v. 16, p. 19-33, 2009a. Disponível em: <http://www.fafich.ufmg. br/ memorandum/a16/alesbello07.htm>. Acesso em: 15 out. 2016.

ALES BELLO, A. Edith Stein o dell'armonia: esistenza, pensiero, fede. Roma: Studium, 2009b.

ALES BELLO, A.; ALFIERI, F.; SHAHID, M. (orgs.). Edith Stein, Hedwig ConradMartius, Gerda Walther: fenomenologia della persona, dellavita e dellacomunità. Cerchiconcentrici. Bari: Edizioni Giuseppe Laterza, 2011.

ALES BELLO, A. Prefácio. In: MAHFOUD, M.; MASSIMI, M. (org.). Edith Stein e a psicologia: teoria e pesquisa. Belo Horizonte: Artesã Editora, 2013 a.

ALES BELLO, A. Prefácio. In: ZWEIG, S. Brasile, terra del futuro. Roma: Elliot, 2013 b.

ALES BELLO, A. Il senso delle cose: per un realismo fenomenologico. Roma: Castelvecchi, $2013 c$.

ALES BELLO, A. Edith Stein: a paixão pela verdade. Trad. José J. Queiroz. Curitiba: Juruá, 2014a.

ALES BELLO, A. Il senso del sacro: dall'arcaicità alla desacralizzazione. Roma: Castelvecchi, 2014b.

ALES BELLO, A. La ricezionedi Edith Stein: um percorsobibliografico. In: MANGANARO, P.; NODARI, F. (eds). Ripartire da Edith Stein: la scoperta di alcuni manoscriti inediti. Brescia: Morcelliana, 2014c. p. 161-167.

ALES BELLO, A. Fenomenologia, ontologia e metafísica em Edith Stein. Memorandum, Belo Horizonte, v. 29, p. 194-207, 2015a. Disponível em: <http:// www.fafich.ufmg.br/memorandum/a29/alesbello09/>. Acesso em: 15 out. 2016. 
ALES BELLO, A.; ALFIERI, F. (eds). Edmund Husserl e Edith Stein: duefilosofi in dialogo. Brescia: Morcelliana, 2015b.

ALES BELLO, A. Pessoa e comunidade: comentários à Psicologia e Ciências do Espirito de Edith Stein. Trad. Miguel Mahfoud e Jacinta Turolo Garcia. Belo Horizonte: Artesã, 2015.

ALES BELLO, A. Edmund Husserl: pensar Deus, crer em Deus. Trad. Jacinta Turolo Garcia e Márcio Luiz Fernandes. São Paulo: Paulus, 2016a.

ALES BELLO, A. Il senso dell 'umano: tra fenomenologia, psicologia e psicopatologia. Roma: Castelvecchi, 2016b.

ALFIERI, F. Die Rezeption Edith Steins. Internationale Edith-Stein-Bibliographie (1942-2012). Festgahefur M. AmataNeyer OCD, Sondernummerdes Edith Stein Jahrbuches, Vorwort v. U. Dobhan OCD, Geleitwort v. H.-B. Gerl-Falkovitz u. A. Ales Bello, Einfuhrung v. F. Alfieri OFM, Echter: Wurzburg, 2012.

ALFIERI, F. Pessoa humana e singularidade em Edith Stein. Prefácio de Juvenal Savian Filho. São Paulo: Perspectiva, 2015.

CORTELLESI, B. L'influenza del pensiero di Edith Stein in Italia. In: SHAHID, M.; CORTELLESI, B. (eds). Ascolto di Edith Stein: voce del mondo. Prefazionedi Angela Ales Bello. Ariccia: Aracne, 2016. p. 69-85.

ALLPORT, G. W. Divenire. Firenze: Editrice Universitaria, 1968.

GHIGI, N. A hilética na fenomenologia: a propósito de alguns escritos de Angela Ales Bello. Memorandum, Belo Horizonte, v. 4, p. 48-60, 2003. Disponível em: <http://www.fafich.ufmg.br/ memorandum/artigos04/ghigi01.htm>. Acesso em: 15 out. 2016.

HUSSERL, E. La crise delle scienze europee e la fenomenologia trascendentale. Trad. E. Filippini. Milano: Il Saggiatore, 1987.

MAHFOUD, M.; MASSIMI, M. (org.). Edith Stein e a psicologia: teoria e pesquisa. Belo Horizonte: Artesã Editora, 2013. 
MAHFOUD, M.; MASSIMI, M. La fenomenologia come metodo per la psicologia. In: BACCARINI, E.; D’AMBRA, M.; MANGANARO, P.; PEZZELLA, A. M. (edd.). Persona, Logos, Relazione: una fenomenologia plurale, scritti in onore di Angela Ales Bello. Roma: Città Nuova, 2011. p. 805-811.

MAHFOUD, M. Das vivências ao mundo: pessoa, comunidade e ciência com Edith Stein. A presença de Angela Ales Bello. In: ALES BELLO, A. Pessoa e comunidade: comentários à Psicologia e Ciências do Espírito de Edith Stein. Trad. Miguel Mahfoud e Jacinta Turolo Garcia. Belo Horizonte: Artesã, 2015. p. 7-17.

MANGANARO, P.; NODARI, F. (eds). Ripartire da Edith Stein: la scoperta di alcuni manoscriti inediti. Brescia: Morcelliana, 2014.

SHAHID, M.; CORTELLESI, B. (eds). La sfida del realismo trascendentale: intorno ad uma proposta di Angela Ales Bello. Roma: Qulture, 2015.

TUROLO GARCIA, J; GOTO, T. A. La ri(costruzione) del pensiero di Edith Stein in Brasile. In: SHAHID, M.; CORTELLESI, B. (edd.). In ascolto di Edith Stein: voce del mondo. PrefazionediAngela Ales Bello. Ariccia: Aracne, 2016. p. 186-199.

VERDUCCI, D. Far vivere l'eredità fenomenologica nella post-modernità. In: BACCARINI, E.; D’AMBRA, M.; MANGANARO, P.; PEZZELLA, A. M. (ed.). Persona, Logos, Relazione: una fenomenologia plurale, scritti in onore di Angela Ales Bello. Roma: Città Nuova, 2011. p. 791-804.

Recebido: 30/12/2016

Received: 12/30/2016

Aprovado: $11 / 04 / 2017$

Approved: 04/11/2017 